\title{
Metacognitive therapy for body dysmorphic disorder patients in Iran: Acceptability and proof of concept
}

Citation for published version (APA):

Rabiei, M., Mulkens, S., Kalantari, M., Molavi, H., \& Bahrami, F. (2012). Metacognitive therapy for body dysmorphic disorder patients in Iran: Acceptability and proof of concept. Journal of Behavior Therapy and Experimental Psychiatry, 43(2), 724-729. https://doi.org/10.1016/j.jbtep.2011.09.013

Document status and date:

Published: 01/06/2012

DOI:

10.1016/j.jbtep.2011.09.013

Document Version:

Publisher's PDF, also known as Version of record

Document license:

Taverne

Please check the document version of this publication:

- A submitted manuscript is the version of the article upon submission and before peer-review. There can be important differences between the submitted version and the official published version of record.

People interested in the research are advised to contact the author for the final version of the publication, or visit the DOI to the publisher's website.

- The final author version and the galley proof are versions of the publication after peer review.

- The final published version features the final layout of the paper including the volume, issue and page numbers.

Link to publication

\footnotetext{
General rights rights.

- You may freely distribute the URL identifying the publication in the public portal. please follow below link for the End User Agreement:

www.umlib.nl/taverne-license

Take down policy

If you believe that this document breaches copyright please contact us at:

repository@maastrichtuniversity.nl

providing details and we will investigate your claim.
}

Copyright and moral rights for the publications made accessible in the public portal are retained by the authors and/or other copyright owners and it is a condition of accessing publications that users recognise and abide by the legal requirements associated with these

- Users may download and print one copy of any publication from the public portal for the purpose of private study or research.

- You may not further distribute the material or use it for any profit-making activity or commercial gain

If the publication is distributed under the terms of Article $25 \mathrm{fa}$ of the Dutch Copyright Act, indicated by the "Taverne" license above, 


\title{
Metacognitive therapy for body dysmorphic disorder patients in Iran: Acceptability and proof of concept
}

\author{
Mehdi Rabiei $^{\text {a }}$, Sandra Mulkens ${ }^{\mathrm{b}, *}$, Mehrdad Kalantari ${ }^{\mathrm{a}}$, Hossein Molavi $^{\mathrm{a}}$, Fatemeh Bahrami ${ }^{\mathrm{c}}$ \\ ${ }^{a}$ University of Isfahan, Dept. of Psychology, Isfahan, Iran \\ ${ }^{\mathrm{b}}$ Maastricht University, Dept. of Clinical Psychological Science, PO Box 616, 6200 MD Maastricht, The Netherlands \\ ${ }^{\mathrm{C}}$ University of Isfahan, Dept. of Counseling, Isfahan, Iran
}

\section{A R T I C L E I N F O}

\section{Article history:}

Received 28 October 2010

Received in revised form

23 September 2011

Accepted 27 September 2011

\section{Keywords:}

Body dysmorphic disorder

Metacognitive therapy

Obsessive-compulsive disorder

Thought-fusion

\begin{abstract}
A B S T R A C T
The purpose of the present study was to determine the effect of metacognitive therapy (MCT) on symptoms of body dysmorphic disorder (BDD) and on symptoms of thought-fusion, by means of a waitlist controlled clinical trial. Participants were referred from dermatology and cosmetic surgery clinics in the city of Isfahan, Iran, and 20 patients were selected on the basis of DSM-IV-TR diagnostic criteria for BDD. They were randomly assigned to either the experimental or the wait-list control group. The YaleBrown Obsessive Compulsive Scale Modified for Body Dysmorphic Disorder (BDD-YBOCS) and the Thought-Fusion Inventory (TFI) were used as the outcome measures. The experimental group received 8 weekly metacognitive intervention sessions. The control group was in the waiting-list until the end of the follow-up. Measures were taken at pre-test, post-test (after 2 months) and follow-up (after 6months). The results of analysis of variance showed that MCT significantly reduced the symptoms of BDD and of thought-fusion, compared to the wait-list. Effects on both outcome measures were maintained at 6-months follow-up.
\end{abstract}

(c) 2011 Elsevier Ltd. All rights reserved.

\section{Introduction}

Body dysmorphic disorder (BDD; previously called dysmorphophobia) is characterized by a preoccupation with an imagined defect in one's appearance or an exaggeration of a slight physical anomaly (American Psychiatric Association, 2000). The largest epidemiological study to date (Rief, Buhlmann, Wilhelm, Borkenhagen, \& Brähler, 2006) reported a BDD prevalence rate of $1.7 \%(95 \% \mathrm{CI}=1.2 \%-2.1 \%)$ in the community. Prevalence rates are significantly higher when examined in psychiatric populations (e.g., 13\%-16\%; Conroy et al., 2008; Grant, Kim, \& Crow, 2001). A recent Dutch study found 3-8\% of the patients in dermatology and plastic surgery clinics of an academic hospital to be suffering from BDD (Vulink et al., 2006).

Surveys of BDD patients attending a psychiatric clinic tend to show an equal sex incidence and sufferers are usually single or separated (Neziroglu \& Yaryura-Tobias, 1993; Phillips \& Diaz, 1997). BDD shares several common characteristics with OCD, such as similar age of onset, sex ratio, severity of symptoms, persistency,

\footnotetext{
* Corresponding author. Tel.: +31 43 3884052; fax: +31 433884196 .

E-mail address: s.mulkens@maastrichtuniversity.nl (S. Mulkens).
}

and high comorbidity with depression and anxiety disorders (Phillips, 2009).

Psychological and pharmacological treatments for BDD have received increasing attention in the past 10 years. Although psychological and pharmacological treatment approaches for BDD have been evaluated, only two RCTs were conducted on CBT and one on medication for BDD in adults. In one study Rosen, Reiter, and Orosan (1995) randomly assigned 54 patients to either group CBT or a no treatment control condition. Groups consisted of four to five patients who attended 8 weekly 2 -h CBT sessions. CBT was significantly more effective than no treatment: clinically significant improvement occurred in $82 \%$ of the CBT group members at the end of treatment, and in $77 \%$ at follow-up 4.5 months later. This study included only females and they were relatively less handicapped than the patients described in other treatment studies. Their concerns were mostly about weight and shape, whereas there was no diagnoseable eating disorder. In the other RCT, Veale et al. (1996), randomly assigned 19 patients to either CBT or a no treatment control condition. Patients attended to 12 weekly individual 1-h sessions. In the CBT condition, 78\% had either no BDD anymore or BDD symptoms in the subclinical range after treatment, whereas all 10 waiting-list patients were still in the clinical range of BDD scores at the end of the trial. In an RCT on medication, Phillips, Albertini, and Rasmussen (2002) randomly assigned 67 
individuals to either 12 weeks of Fluoxetine or a placebo. Fluoxetine was superior to placebo. To summarize, evidence of CBT as a favorable treatment for BDD is still scarce and no RCT has directly compared CBT to medication yet.

The present study aims to add knowledge to treatment effectiveness for BDD by conducting an RCT comparing Metacognitive Therapy (MCT; Wells, 2009) with a no treatment control group. Metacognition refers to knowledge or beliefs about thinking and strategies used to regulate and control thinking processes (Moses \& Baird, 1998). MCT is based on the idea that metacognitions cause a particular pattern of responding to inner experiences such as worry and rumination that maintains negative emotions and strengthens negative thought. In MCT not the content (per se) of cognitions (e.g., negative, irrational cognitions about the self (and appearance), the world, and other people) is addressed - as is done in cognitive therapy- but merely beliefs about thinking (metacognitive beliefs) and the process itself are the focus of treatment. In other words, CT attempts to modify the content of perseverative thinking, i.e., appraisals, rather than the metacognitive processes which perpetuate the continued maladaptive processing. With respect to content, certain thoughts (eg., about their appearance) and intrusions (urges, images and emotions) are referred to. By the process, the factors that maintain these kinds of intrusions are referred to. For example, the type of attention (eg., self-focused attention) may influence thinking style in such a way that information which comes in through internal feelings and thoughts is especially paid attention to and may increase rumination and worry. This does not mean that BDD patients do not make appraisals of inflated responsibility or overestimate threat but that these occur in the stream of rumination/worry. It follows that modifying the processes and metacognitions that give rise to the stream of worry could be a more effective treatment approach than just focusing on the actual content of thoughts. Evidence of the relationships between metacognitions and OCD symptoms has been demonstrated using non-patient samples (Fisher \& Wells, 2008; Myers \& Wells, 2005; Wells, Gwilliam, \& CartwrightHatton, 2001), both in experimental studies (Fisher \& Wells, 2005a), and patient group comparisons (Janeck, Calamari, Riemann, \& Heffelfinger, 2003).

The metacognitive model of OCD (Wells, 1997) is based on the more generic model, the Self-Regulatory Executive Function Model (S-REF) and proposes that intrusive thoughts activate metacognitive knowledge which in turn guides maladaptive processing. In other words, specific metacognitive beliefs lead to the cognitive attentional syndrome (CAS). The metacognitive beliefs concern the dangerousness and significance of intrusive thoughts/feelings. For example, BDD patients may have so-called 'positive' metacognitive beliefs about the consequences of their body ruminations. They believe that these thoughts lead them to pay much more attention to their appearance and, as a consequence, provide a condition where other people see them as less ugly and which reduces the others' negative beliefs about them. Continuing body rumination, however, causes negative metacognitive beliefs about these persevered negative feelings and thoughts to increase and, eventually, the patient perceives them as dangerous and uncontrollable events. This situation makes them more anxious and irritable.

Cooper and Osman (2007) suggested that patients with BDD do indeed engage in metacognitive processing in relation to their concerns with appearance. They report attempts to control, correct, appraise, and regulate their thinking in relation to images and also in relation to thoughts associated with their illness-related concerns. Thus, as suggested by Veale (2004), metacognition may be an important feature of information processing in BDD and may be one way in which the symptoms of the disorder are maintained. Theoretically, therefore, it may be an important dimension to be incorporated into a cognitive model of BDD. Further research is needed into the phenomenon of metacognition, including its characteristics, functions, and role in the maintenance of the distressing symptoms of BDD. Imagery has been accorded a particularly important role in the maintenance of BDD, where mental images of the self are thought to be a particularly central feature of a cognitive conceptualization (Veale, 2004, 1996).

Metacognitive therapy has been pilot tested for OCD in a case series (Fisher \& Wells, 2008) and as a component of small group treatment (Rees \& Van Koesveld, 2008). According to some larger studies it seems that metacognitive therapy is an effective intervention for OCD (Fisher, 2009; Wells, 2000; Fisher \& Wells, 2005b). Following the S_REF model the cognitive attentional syndrome (CAS) is a feature of many disorders. There is clear evidence of CAS in BDD (e.g. worry \& rumination, threat monitoring, mirror gazing and mirror checking, and coping behaviors that backfire). Thus, a treatment that would decrease CAS and metacognition associated with it should be effective for BDD. The present study investigated the effects of metacognitive therapy on BDD symptoms, as BDD is considered an OCD-spectrum disorder. As a manipulation check, the effect on thought-fusion manifestations was also investigated.

\section{Method}

\subsection{Participants}

Patients were drawn from $(n=100)$ consecutive referrals made by general practitioners and psychiatrists to dermatologist and cosmetic surgery clinics in the city of Isfahan, Iran. BDD diagnosis was established using the structured clinical interview for DSM-IV diagnoses (SCID, based on the Diagnostic and Statistical Manual of Mental Disorders - 4th Edition, Text Revision (DSM-IV-TR; American Psychiatric Association, 2000). The diagnoses were made by the first author, holding a master's degree in clinical psychology. Thirty-one individuals met the criteria for diagnosis of BDD set by DSM-IV-TR, of which 20 individuals were willing to participate in our treatment study; their major problem was BDD. See Fig. 1 for a flow chart.

Twenty patients were, thus, recruited (18 females), ages ranging from 16 to 37 years ( mean $=25.2 ; \mathrm{SD}=6.5$ ). Seventeen $(85 \%)$ of the participants were single and 3 were married. Their socio-economic status was average or above average. Classification of socioeconomic status was based on coding of the subjects' income, education and job. Also, they all had some high school diploma and university education. None of the patients were currently taking psychotropic medication (4 patients had previously taken clomipramine and another one fluvoxamine, buspirone and lithium carbonate). The duration of their BDD ranged from 1 to 10 years. Fifty-five percent of the patients had a single diagnosis of BDD, and 45 percent had an additional diagnosis. Two patients met the criteria for additional major depressive disorder. One patient met the criteria for social phobia, and one patient had comorbid OCD. The participants in the experimental group had one or more of the following concerns: facial skin $(n=3)$, hair $(n=2)$, breasts $(n=1)$, eyes $(n=1)$, and shape of the nose $(n=3)$. The participants in the control group had the following concerns: facial skin $(n=4)$, hair $(n=2)$, breasts $(n=1)$, eyes $(n=1)$, and shape of nose $(n=2)$. Table 1 provides general characteristics of the study sample.

\subsection{Design}

The design of this study was experimental with pre-test, post-test and follow-up. After completion of the baseline assessment, patients who met the entry criteria and agreed to participate in the study were randomly assigned to one of two 


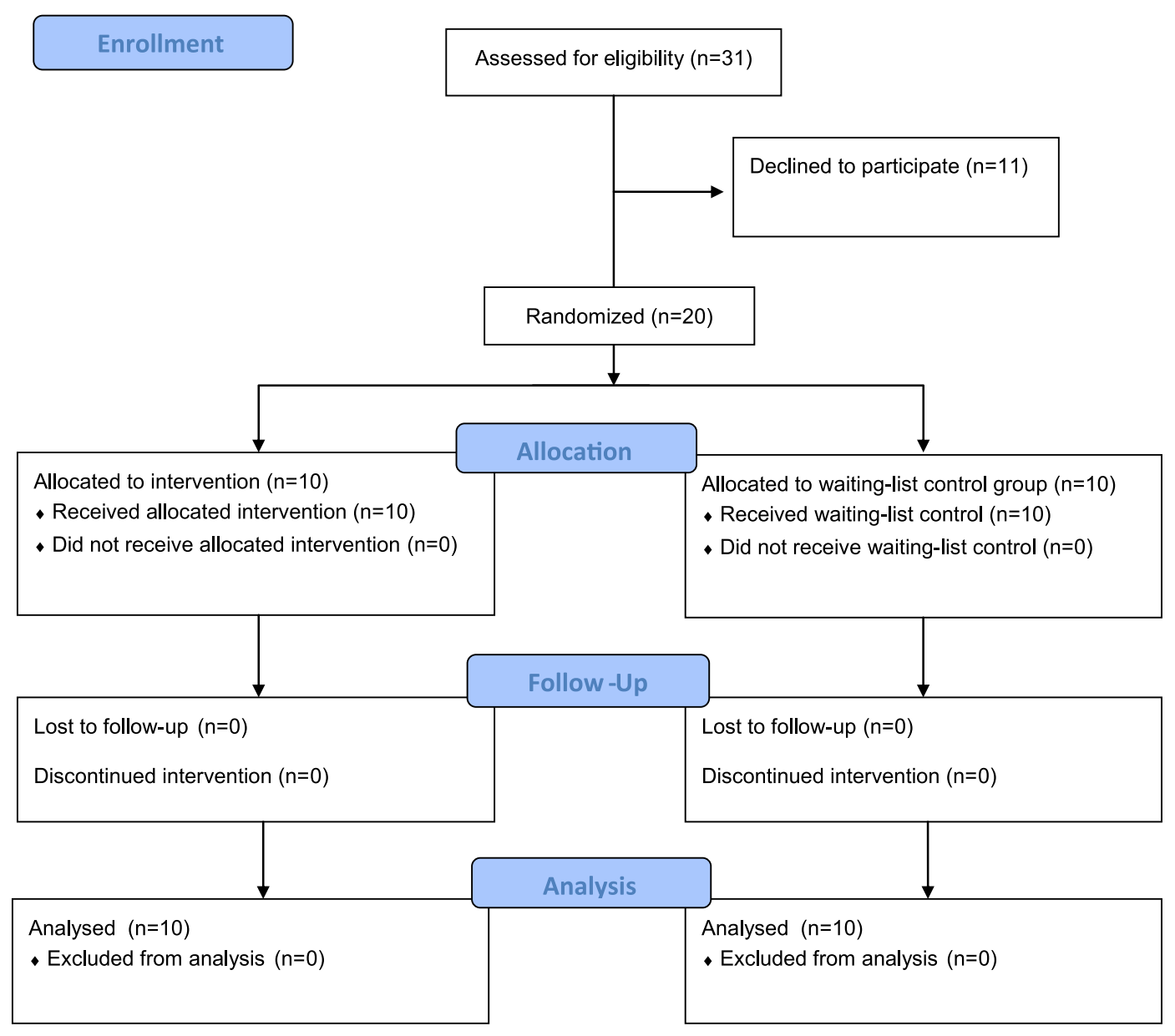

Fig. 1. CONSORT 2010 Flow Diagram.

trial groups: (1) MCT, (2) wait-list. Randomization - by the first author - was based on Simple Sampling to ensure balanced group assignments. Participants were informed about the assigned treatment only after the completion of the baseline measurements. The experimental group (10 participants, 1 male) received 8 sessions of $45-60 \mathrm{~min}$ of MCT while the control group (10 participants, 1 male) remained in the waiting-list and received no intervention. After the intervention, a post-test, and after 6-months, a follow-up measurement was taken. There was one between subjects variable (Treatment: MCT vs Waiting) and there was 1 within subjects variable (Time, with three levels: pre, post and follow-up). The dependent variables were BDD symptoms and thought-fusion symptoms in BDD.

\subsection{Intervention}

Patients received eight individual weekly sessions of metacognitive therapy (MCT) of 45-60 min duration. Homework was a component of treatment, and the metacognitive therapy was carried out on the basis of Wells' manual (2000). In order to administer the Wells model to BDD, some modifications were made.

The aim of MCT for BDD is to increase patients' awareness of the role that metacognition plays in maintaining their symptoms. The goal is to enable patients to move from treating their thoughts about their appearance as facts to objectively evaluate their appearance as merely mental events not requiring further processing. This is accomplished by modifying metacognitive beliefs about appearance and rituals, reducing levels of rumination, worry, self-focused attention and replacing maladaptive coping strategies with adaptive coping strategies which facilitate the development of functional processing.

In the first session, an idiosyncratic case formulation based on the metacognitive model of BDD was developed with each patient. This was followed by socialization strategies in which the therapist introduces the idea that a central problem is not the occurrence of obsessional thoughts, doubts, feelings, but the meanings and responses that are applied to them. The therapist emphasizes the idea that it is the patient's belief about these events and the way the

Table 1

Means (and SDs) of general characteristics of the patients (age, education, socioeconomic status, duration of past medication, 'single concern' versus 'multiple concerns', comorbidity percentage and duration of BDD).

\begin{tabular}{lll}
\hline & Experimental & Control \\
\hline Age & $23.7(6.5)$ & $26.6(6.6)$ \\
Education & $2.1(.73)$ & $1.8(.78)$ \\
High school diploma & $20 \%$ & $40 \%$ \\
Bachelor & $50 \%$ & $40 \%$ \\
Master & $30 \%$ & $20 \%$ \\
Socio-economic status & $2.4(.51)$ & $2.3(.67)$ \\
Low & $0 \%$ & $10 \%$ \\
Average & $60 \%$ & $50 \%$ \\
High & $40 \%$ & $40 \%$ \\
Past medication in years & $1.3(.67)$ & $1.3(.48)$ \\
Number of concerns & $2.1(1.4)$ & $2.7(1.8)$ \\
Percentage with comorbid diagnoses & $40 \%$ & $50 \%$ \\
Duration of BDD in years & $11.1(14.5)$ & $11.2(14.5)$ \\
\hline
\end{tabular}


patient relates to them that cause the problem of BDD. Thoughtfusion beliefs were then targeted using verbal reattribution and within session behavioral experiments in which patients were trained to respond to their preoccupation with 'detached mindfulness' (Wells, 2000; Wells \& Mathews, 1994). Homework assignments consisted of watching their obsessive thoughts about their body as an observer and not to engage with them in any way. Due to this practice, they were able to detach from internal thoughts and feelings and to do this instead of ruminating, suppressing thoughts, conducting behavioral rituals or behaviors in response to their obsessional thoughts. Patients were asked to simply notice their preoccupation and choose to let the thought decay naturally.

'Detached mindfulness' is achieved by giving the patient within session practice of the strategy with emotionally neutral material and is then practiced in response to their preoccupation. This strategy aims to increase awareness of the maintaining role of metacognitive beliefs in BDD, whilst at the same time modify both metacognitive beliefs about appearance, as well as positive and negative beliefs about rituals. Patients were then asked to implement the technique consistently between therapy sessions. Subsequent treatment sessions involved further practice of 'detached mindfulness' and modification of beliefs about the necessity of performing rituals in response to preoccupation (positive metacognitive belief about rumination and worry).

Both positive metacognitive beliefs about rituals (e.g., 'my rituals prevent me from looking terrible') and negative metacognitive beliefs about rituals (e.g., 'my compulsions are uncontrollable and will make me go mad') were addressed in therapy. The next step in treatment was to modify the maladaptive internal criteria that BDD patients use to guide their overt and covert rituals. Patients usually will continue to perform their rituals until an internal goal state is achieved and use a range of maladaptive strategies in trying to determine whether a situation is safe or dangerous. Attentional strategies, such as hypervigilance, are often used for both internal and external threat cues. Patients frequently display elevated cognitive self-consciousness and engage in the monitoring of mental events for absence/presence of intrusive thoughts. Following advantages-disadvantages analysis of these behaviors, patients were asked to ban their maladaptive attentional strategies and instead were reminded to use feelings of anxiety or inappropriate monitoring as a cue to implement detached mindfulness. The final two treatment sessions focused on relapse prevention and further modification of positive and negative metacognitive beliefs which included erroneous beliefs about the recurrence of emotion and deviations in mood. Relapse prevention involved the development of a therapy blueprint which includes a written and diagrammatic formulation of the metacognitive model of BDD. A detailed account of the main therapeutic strategies used during treatment was also provided, along with a specific plan for the patient to implement in guiding their thinking and behavioral style in responses to future negative moods. Patients were encouraged to implement these strategies to maintain and strengthen the gains made over the course of treatment. For further details on the treatment delivered in this study, see Wells (1997; 2000).

After the follow-up, the control group also received 5 sessions of MCT, for ethical reasons. The content of these sessions was comparable to the content of the experimental sessions but due to financial and time limitations, the number of sessions was less ( 5 instead of 8 ), whereas the duration of the sessions was longer (60-70 min instead of $45-60 \mathrm{~min}$ ).

\subsection{Treatment integrity}

Treatment rationale, treatment model, treatment formulations, therapeutic strategies and treatment targets were according to the
MCT manual adapted for BDD patients and the therapist was obliged to conduct the treatment precisely according to the MCT manual adapted for BDD patients. The intervention was conducted by one master's degree clinical psychologist who had passed a 6month training of MCT. At the end of the sessions the first author and the therapist discussed the contents of the sessions, to ensure those sessions were based on MCT.

\subsection{Measurements}

The following measures were completed at the beginning and end of the intervention (that is, 2-months after the start), and at 6months follow-up.

\subsubsection{Yale-Brown Obsessive Compulsive Scale Modified for Body}

Dysmorphic Disorder (BDD-YBOCS; Phillips \& Hollander et al., 1997)

This is a reliable and valid 12-item semi-structured clinician administered instrument that evaluates current BDD severity. It assesses BDD-related preoccupations, repetitive behaviors, insight, and avoidance (Phillips, 2009). The reliability and validity of the BDD-YBOCS Farsi translated version was demonstrated by Rabiei, Khormdel, Kalantari, and Molavi (2010) in both healthy and clinical samples. They showed that alpha coefficients ranged from .78 to .93 for the BDD-YBOCS total score and for its subscales (preoccupations, repetitive behaviors).

\subsubsection{Thought Fusion Instrument (TFI; Wells et al., 2001)}

This is a 14-item self-report scale that assesses metacognitive beliefs about the meaning, significance and dangerousness of intrusive thoughts. It consists of items tapping TAF, TEF and TOF. Each item is rated on a $0-100$ scale (where ' 0 ' represents 'I do not believe this at all', and ' 100 ' represents 'I am completely convinced that this thought is true'). There are limited psychometric data available, but Gwilliam, Wells, and Cartwright-Hatton (2004) obtained excellent reliability (Cronbach's alpha is .89). The scale appears to have a single factor structure combining all items, and preliminary evidence supports its convergent and discriminate validity (Gwilliam, 2001). Moreover, Khormdel, Rabiei, and Molavi (2010) showed that the TFI Farsi translated version in both healthy and clinical samples had proper reliability and validity.

Patients' satisfaction with treatment, therapist, content of sessions, strategies taught, outcome and goals achieved were assessed at post-treatment on a 6-point scale (1-6 where ' 1 ' indicates minimum satisfaction and ' 6 ' indicates maximum satisfaction).

\subsection{Data reduction and analysis}

First, we conducted descriptive statistics, including distribution of continuous variables. We then calculated patients' satisfaction with treatment. Two repeated measures analyses of variance (ANOVAs) were conducted to examine the effectiveness of metacognitive therapy (MCT) on symptoms of BDD and thought-fusion symptoms in BDD, respectively. Effect sizes were computed by using Cohen's d. Finally, clinically significant change percentages were calculated for each group using a cut-off score of 20 on the BDD-YBOCS.

\section{Results}

The results of Chi Square tests and Mann-Whitney $U$-test showed that the differences between the two groups were not significant with regard to gender, education, socio-economic status, and percentage suffering from comorbid diagnoses $(p>.05)$. 
Table 2

Means (and SDs) for BDD symptoms and Thought-Fusion at pre -treatment, posttreatment, and follow-up in the experimental and the control group.

\begin{tabular}{|c|c|c|c|c|c|c|}
\hline & \multicolumn{3}{|c|}{ Experimental $(N=10)$} & \multicolumn{3}{|c|}{ Control $(N=10)$} \\
\hline & Pre & Post & Follow-up & Pre & Post & Follow-up \\
\hline BDD-Y & $30.1(6.5)$ & $20.1(6.9)$ & $20.8(5.85)$ & $30.8(8.4)$ & $31.2(8.6)$ & $30.8(8.5)$ \\
\hline TFI & 697 (1.6) & $406(1.7)$ & $375(9.55)$ & 631 (1.99) & $688(1.5)$ & $680(1.2)$ \\
\hline
\end{tabular}

Moreover, the results of an independent samples $t$-test showed that the differences between the two groups were not significant with regard to age, duration of past medication, number of concerns, and duration of $\operatorname{BDD}(p>.05)$.

\subsection{Treatment refusers and drop-outs}

There were no drop-outs in this study. The mean number of sessions that participants attended to was 6; Two participants were absent for 2 sessions because of their final exams. We believe that the reasons for the absence of drop-outs are as follows:

1- The participants were all highly motivated, well-educated and volunteers

2- There was no charge for participation

\subsection{Patients' satisfaction}

The scores on patient's satisfaction with treatment, therapist, content of sessions, strategies taught, outcome and goals achieved, assessed at post-treatment on a 6-point scale, ranged from 4.0 to 6.0 (mean $=4.85, \mathrm{SD}=.93$ ). This indicates that satisfaction of the patients about the treatment was moderate to high.

\subsubsection{Effects of treatment on BDD and TFI symptoms}

The means of both dependent variables and standard deviations of pre-test, post-test, and follow-up tests are presented in Table 2.

The assumption of normality was not rejected by the Shapiro-Wilk test. Also the equality of population variances was not rejected by Levene's test.

The two groups did not differ significantly at pre-test with regard to BDD and TFI symptoms $(\mathrm{t}(18)=-.21, p>.0 .05$ and $\mathrm{t}(18)=.81, p>.05$, for both measurements, respectively).

The 2 (Group: treatment vs waiting) $\times 3$ (Time: pre vs post vs follow-up) repeated measures ANOVA with BDD symptoms as the outcome variable revealed a significant main effect of Time $(F(2$, $17)=8.5 ; p<.005)$ and a significant interaction effect of Group and Time $(F(2,17)=11.7 ; p<.005)$. Inspection of the means indicates that individuals in the treatment group improved on BDD symptoms whereas control individuals remained stable across all time points. The largest improvement on BDD scores was observed between pre-test and post-test; an independent samples $t$-test with BDD change score (post-test minus pre-test) as the dependent variable was significant $(t(18)=-4.3, p<.001$; mean change scores being -10 and .4 for the experimental and control group, respectively). Between post-test and follow-up, the scores of both groups remained stable; that is, changes scores from post-test to follow-up were not significantly different for both groups $(t(18)=1.1 p>.05$; mean change scores being .7 and -.4 for the experimental and control group, respectively), indicating that the experimental group's improvement persisted at follow-up whereas the control groups' relatively unchanged higher scores persisted.

The 2 (Group: treatment vs waiting) $\times 3$ (Time: pre vs post vs follow-up) repeated measures ANOVA with TFI symptoms as the outcome variable revealed a similar pattern: there was a significant main effect of Time $(F(2,17)=6.9 ; p<.01)$ and a significant interaction effect of Group and Time $(F(2,17)=13.8 ; p<.001)$. Inspection of the means indicates that individuals in the treatment group improved on TFI symptoms whereas control individuals remained stable. Here also, the largest improvement on TFI scores was observed between pre-test and post test; a t-test with TFI change score (post-test minus pre-test) as the dependent variable was significant $(t(18)=-5.2, p<.001$; mean change score being -291 and 57 for the experimental and control group, respectively). Between post-test and follow-up, the scores of both groups remained stable; that is, changes scores from post-test to follow-up were not significantly different for both group $(t(18)=-.5 p>.05$, mean changes scores being -30 and -8 , for the experimental and control group, respectively), indicating that the experimental group's TFI score improvement persisted at follow-up whereas the control groups' unchanged higher TFI scores remained.

The effect size of MCT in this study as compared to the waitinglist group was Cohen's $d=.33$ for BDD symptoms and Cohen's $d=.51$ for TF. At post-test, 70 percent of the patients in the experimental group had a clinically significant recovery score $(20$ or below) on the BDD-YBOCS versus none of the patients in the wait-list control group. At follow-up, these percentages were 60 versus 0 in the experimental and the control group, respectively.

Overall, the analyses showed that MCT had a significant effect on reducing the symptoms of BDD and TFI in BDD patients compared with the control group.

\section{Discussion}

Despite recent advances in developing effective treatments for Body Dysmorphic Disorder, much less treatment outcome research has been carried out on BDD than on any other serious mental disorder, and more treatment research is urgently needed. The present study aimed to further explore treatment possibilities for BDD with regard to metacognitive components, as Cooper and Osman (2007) have shown that there metacognitions and BDD symptoms are related.

MCT deals with the way patients with BDD think and it assumes that the problem rests with inflexible and recurrent styles of thinking in response to negative thoughts, feelings and beliefs. In this study, the patients were taught that metacognitive beliefs such as the belief that worry or rumination is an effective desirable coping strategy - are an important factor contributing to the maintenance of BDD. However, metacognitive beliefs do not provide information that disconfirms negative beliefs or appraisals.

This is the first study to evaluate the effects of MCT on ThoughtFusion symptoms in BDD. The results showed that this form of treatment was associated with reductions in Thought-Fusion symptoms in BDD. The post-treatment effect sizes for MCT were very large and support the continued evaluation of MCT in severe and enduring mental health problems.

Patients appeared to tolerate the treatment well and were able to comply with their homework. This is congruent with the MCT theory of Wells (Fisher, 2009; Fisher \& Wells, 2008; Wells, 2000, 2009; Wells \& Matthews, 1994) and studies about the efficacy of MCT on emotional disorders (e.g. Obsessive-Compulsive Disorder, Generalized Anxiety Disorder and Post Traumatic Stress Disorder).

The effect size of MCT in this study as compared to the waitinglist group was Cohen's $d=.33$ for BDD symptoms and Cohen's $d=.51$ for TF. In comparison, Rosen et al. (1995) reported an $82 \%$ response rate in BDD patients randomized to a CBT group treatment. Also, in a meta-analysis done by Williams, Hadjistavropoulos, and Sharpe (2006), both medication and CBT were shown to be effective in treating BDD, although CBT was associated with significantly higher effect sizes than medication $(d=1.78$ and 
$d=.92$, respectively). Thus, CBT seems to be a promising treatment approach for BDD. Future research, studying the effects of CBT directly against those of MCT and medication in bigger patient samples, may show which of these therapies would be more effective in BDD patients.

There are also limitations in this study, meaning that the results need to be interpreted with some caution. First, MCT is a relatively new technique, which has not yet been investigated extensively in OCD, only by means of case studies. The effects should be interpreted with a little caution, as they might partly be explained by treatment novelty. Next, because of the small sample size, it was not possible to compare MCT to another form of treatment to control for the effect of therapist attention. Furthermore, although MCT was manual-based and efforts have been made to ensure that the intervention was according to MCT only (and not other therapies), it would be better if treatment sessions were recorded and checked by independent raters. As the participants in this project were volunteers, highly educated, young and mostly female and single, generalization of the findings should be done only with caution. Another limitation of the study may go back to the inequality of the participants in both groups concerning gender. Next, the first author was aware of the participant's group membership. Furthermore, delusional patients could not be distinguished from non-delusional patients, as we did not assess delusionality. Since our patients were all in the mild-moderate YBOCS scores range, and had relative lack of general comorbidity, we believe that they were not delusional, and perhaps are more cognitively flexible. Next, the items of TOF, TEF, and TAF scales originally designed for OCD- were not adapted for specific assessment of BDD (and thoughts about appearance). Although we feel that there are a lot of similarities between OCD and BDD, the results should be cautiously generalized to a BDD population. Finally, there were no other self-report BDD symptom or quality of life scales which limits the results. In future studies it is recommended that the effects of MCT, CBT and medication therapy be directly compared. Moreover, it is suggested that non volunteer participants, lower educated and other age ranges, and particularly male and married participants, with larger sample sizes.

All in all, it can be concluded that MCT is an effective treatment for BDD. Furthermore, the effect was somewhat more pronounced in Thought-Fusion symptoms than in BDD symptoms. This paper aimed to describe the aspects of the metacognitive model and treatment of BDD. It is possible that an explicit treatment focus on metacognition could improve the absolute efficacy rates for this disorder. Whilst studies evaluating the efficacy of metacognitive therapy are in their infancy, the results thus far are promising and merit further large scale investigations. A fascinating and enlightening study would be a direct comparison of MCT with CT, CBT and drug therapy. This would further highlight the differences and similarities between treatment approaches and their putative mechanisms of action in BDD.

\section{References}

American Psychiatric Association. (2000). Diagnostic and statistical manual of mental disorders. Text Revision (4th ed.). Washington DC: Author.

Conroy, M., Menard, W., Fleming-Ives, K., Modha, P., Cerullo, H., \& Phillips, K. A. (2008). Prevalence and clinical characteristics of body dysmorphic disorder in an adult inpatient setting. General Hospital Psychiatry, 30, 67-72.

Cooper, M., \& Osman, S. (2007). Metacognition in body dysmorphic disorder- A preliminary exploration. Journal of Cognitive Psychotherapy: an International Quarterly, 21, 148-155.
Fisher, P. L. (2009). Obsessive compulsive disorder: a comparison of CBT and the metacognitive approach. International Journal of Cognitive Therapy, 2, 107-122.

Fisher, P. L., \& Wells, A. (2005a). Experimental modification of beliefs in obsessivecompulsive disorder: a test of the metacognitive model. Behavior Research $\mathcal{E}$ Therapy, 43, 821-829.

Fisher, P. L., \& Wells, A. (2005b). How effective are cognitive and behavioral treatments for obsessive-compulsive disorder? A clinical significance analysis. Behavior Research \& Therapy, 43, 1543-1558.

Fisher, P. L., \& Wells, A. (2008). Metacognitive therapy for obsessive-compulsive disorder: a case series. Journal of Behavior Therapy and Experimental Psychiatry, 39, 117-132.

Grant, J. E., Kim, S. W., \& Crow, S. J. (2001). Prevalence and clinical features of body dysmorphic disorder in adolescent and adult psychiatric inpatients. Journal of Clinical Psychiatry, 62, 517-522.

Gwilliam, P. D. H. (2001). An investigation into the cognitive predictors of obsessivecompulsive symptoms. Unpublished manuscript, University of Manchester.

Gwilliam, P. D. H., Wells, A., \& Cartwright-Hatton, S. (2004). Does meta-cognition or responsibility predict obsessive-compulsive symptoms: a test of the metacognitive model. Clinical Psychology and Psychotherapy, 11, 137-144.

Janeck, A. S., Calamari, J. E., Riemann, B. C., \& Heffelfinger, S. K. (2003). Too much thinking about thinking? Metacognitive differences in obsessive-compulsive disorder. Journal of Anxiety Disorders, 17, 181-195.

Khormdel, K., Rabiei, M., \& Molavi, H. (2010). Psychometric properties of the Thought Fusion Instrument (TFI) in students. Iranian Journal of Psychiatry and Clinical Psychology, 16, 74-78.

Moses, L. J., \& Baird, J. A. (1998). Metacognition. In R. A. Wilson, \& F. C. Keil (Eds.), The MIT encyclopedia of the cognitive sciences. Cambridge, MA: MIT Press.

Myers, S. G., \& Wells, A. (2005). Obsessive compulsive symptoms: the contribution of metacognitions and responsibility. Journal of Anxiety Disorders, 19, 806-817.

Neziroglu, F., \& Yaryura-Tobias, J. A. (1993). Body dysmorphic disorder: phenomenology and case descriptions. Behavioural Psychotherapy, 21, 27-36.

Phillips, K. A. (2009). Understanding body dysmorphic disorder. New York: Oxford University Press.

Phillips, K. A., Albertini, R. S., \& Rasmussen, S. A. (2002). A randomized placebocontrolled trial of fluoxetine in body dysmorphic disorder. Archives of General Psychiatry, 59, 381-388.

Phillips, K. A., \& Diaz, S. F. (1997). Gender differences in body dysmorphic disorder Journal of Nervous \& Mental Disease, 185, 570-577.

Phillips, K. A., Hollander, E., Rasmussen, S. A., Aronowitz, B. R., DeCaria, C., \& Goodman, W. K. (1997). A severity rating scale for body dysmorphic disorder: development, reliability, and validity of a modified version of the Yale-Brown Obsessive Compulsive Scale. Psychopharmacology Bulletin, 33, 17-22.

Rabiei, M., Khormdel, K., Kalantari, K., \& Molavi, H. (2010). Validity of the YaleBrown Obsessive Compulsive Scale modified for Body Dysmorphic Disorder (BDD) in students of the University of Isfahan. Iranian Journal of Psychiatry and Clinical Psychology, 15, 343-350.

Rees, C. S., \& Van Koesveld, K. E. (2008). An open trail of group metacognitive therapy for Obsessive-Compulsive disorder. Journal of Behavior Therapy and Experimental Psychiatry, 39, 451-458.

Rief, W., Buhlmann, U., Wilhelm, S., Borkenhagen, A., \& Brähler, E. (2006). The prevalence of body dysmorphic disorder: a population-based survey. Psychological Medicine, 36, 877-885.

Rosen, J. C., Reiter, J., \& Orosan, P. (1995). Cognitive-behavioral body image therapy for body dysmorphic disorder. Journal of Consulting and Clinical Psychology, 63, 263-269.

Veale, D. (1996). Body dysmorphic disorder. A survey of fifty cases. British Journal of Psychiatry, 169, 196-201.

Veale, D. (2004). Advances in a cognitive behavioral model of body dysmorphic disorder. Body Image, 1, 113-125.

Veale, D., Gournay, K., Dryden, W., Boocock, A., Shah, F., Willson, R., et al. (1996). Body dysmorphic disorder: a cognitive behavioural model and pilot randomised controlled trial. Behavioural Research and Therapy, 34, 717-729.

Vulink, N. C., Sigurdsson, V., Kon, M., Bruijnzeel-Koomen, C. A., Westenberg, H. G., \& Denys, D. (2006). Body dysmorphic disorder in 3-8\% of patients in outpatient dermatology and plastic surgery clinics. Nederlands Tijdschrift voor Geneeskunde, 150, 97-100.

Wells, A. (1997). Cognitive therapy of anxiety disorders: A practice manual and conceptual guide. Chichester, UK: Wiley.

Wells, A. (2000). Emotional disorders and metacognition: Innovative cognitive therapy. Chichester, UK: Wiley.

Wells, A. (2009). Metacognitive therapy for anxiety and depression. New York: The Guilford Press.

Wells, A., Gwilliam, P. D. H., \& Cartwright-Hatton, S. (2001). The Thought Fusion Instrument. Unpublished Scale. Manchester: University of Manchester.

Wells, A., \& Mathews, G. (1994). Attention and emotion: A clinical perspective. Hove, UK: Lawrence Erlbaum \& Associates.

Williams, J., Hadjistavropoulos, T., \& Sharpe, D. (2006). A meta-analysis of psychological and pharmacological treatments for Body Dysmorphic Disorder. Behaviour Research and Therapy, 44, 99-111. 